\title{
Cancer-associated fibroblasts induce high mobility group box 1 and contribute to resistance to doxorubicin in breast cancer cells
}

\author{
Kamolporn Amornsupak', Tonkla Insawang ${ }^{1}$, Peti Thuwajit ${ }^{1}$, Pornchai O-Charoenrat ${ }^{2}$, Suzanne A Eccles ${ }^{3}$ \\ and Chanitra Thuwajit ${ }^{*}$
}

\begin{abstract}
Background: Cancer-associated fibroblasts and high mobility group box 1 (HMGB1) protein have been suggested to mediate cancer progression and chemotherapy resistance. The role of such fibroblasts in HMGB1 production in breast cancer is unclear. This study aimed to investigate the effects of cancer-associated fibroblasts on HMGB1 expression in breast cancer cells and its role in chemotherapeutic response.
\end{abstract}

Methods: Breast cancer-associated fibroblasts (BCFs) and non-tumor-associated fibroblasts (NTFs) were isolated from human breast cancers or adjacent normal tissues and established as primary cultures in vitro. After confirmation of the activated status of these fibroblasts, conditioned-media (CM) were collected and applied to MDA-MB-231 human triple negative breast cancer cells. The levels of intracellular and extracellular HMGB1 were measured by real-time PCR and/or Western blot. The response of BCF-CM-pre-treated cancer cells to doxorubicin (Dox) was compared with those pre-treated with NTF-CM or control cultures. The effect of an HMGB1 neutralizing antibody on Dox resistance induced by extracellular HMGB1 from non-viable Dox-treated cancer cells or recombinant HMGB1 was also investigated.

Results: Immunocytochemical analysis revealed that BCFs and NTFs were alpha-smooth muscle actin (ASMA) positive and cytokeratin 19 (CK19) negative cells: a phenotype consistent with that of activated fibroblasts. We confirmed that the CM from BCFs (but not NTFs), could significantly induce breast cancer cell migration. Intracellular HMGB1 expression was induced in BCF-CM-treated breast cancer cells and also in Dox-treated cells. Extracellular HMGB1 was strongly expressed in the CM after Dox-induced MDA-MB-231 cell death and was higher in cells pre-treated with BCF-CM than NTF-CM. Pre-treatment of breast cancer cells with BCF-CM induced a degree of resistance to Dox in accordance with the increased level of secreted HMGB1. Recombinant HMGB1 was shown to increase Dox resistance and this was associated with evidence of autophagy. Anti-HMGB1 neutralizing antibody significantly reduced the effect of extracellular HMGB1 released from dying cancer cells or of recombinant HMGB1 on Dox resistance.

Conclusions: These findings highlight the potential of stromal fibroblasts to contribute to chemoresistance in breast cancer cells in part through fibroblast-induced HMGB1 production.

Keywords: Breast cancer, Cancer-associated fibroblast, HMGB1, Chemoresistance

\footnotetext{
* Correspondence: cthuwajit@yahoo.com

'Department of Immunology, Faculty of Medicine Siriraj Hospital, Mahidol

University, Bangkok 10700, Thailand

Full list of author information is available at the end of the article
} 


\section{Background}

Breast cancer is the most common cancer in females worldwide [1] including Thailand [2]. The standard treatment of breast cancer patients is surgery and chemotherapy. Chemotherapy can be used before (neoadjuvant) or after surgery, with or without other interventions, e.g. radiation or targeted therapy, depending on the subtype and stage of the disease [3]. Unresponsiveness to chemotherapeutic drugs, however, is still the main problem. It has been reported that about $30 \%$ of early stage breast cancer patients have a risk of developing drug resistance and cancer recurrence [4]. Resistance is primarily due to the inherent genetic instabilities of cancer cells; however, the resistance acquired during cancer progression and in particular the role of the tumor microenvironment, has also been investigated [5]. A variety of bioactive molecules are secreted by fibroblasts in the tumor microenvironment which can promote tumor growth, metastasis, neoangiogenesis and drug resistance [6-8]. Interactions between cancer cells and stromal fibroblasts reportedly contribute to the chemoresistance of pancreatic ductal adenocarcinoma. The mechanisms described include epigenetic regulation of apoptotic genes in cancer cells [9] and the increased secretion of nitric oxide leading to release of interleukin-1 $\beta$ by the tumor cells that provides protection from anticancer drugs [10].

Moreover, activated fibroblasts in breast cancer have been correlated with the aggressiveness of the disease [11-14] and the induction of acquired chemoresistance [15]. The stromal gene expression pattern has revealed the potential to predict resistance to preoperative chemotherapy with 5-fluorouracil, epirubicin and cyclophosphamide [16]. Collagen type I secreted by fibroblasts can decrease chemotherapeutic drug uptake into cancer cells leading to the regulation of the response to several agents [17]. In addition, critical roles of fibroblasts have been described in tamoxifen resistance via activation of growth factor-related signaling pathways or increased mitochondrial function resulting in an anti-apoptotic effect $[18,19]$. Taken together, this evidence suggests that targeting stromal fibroblasts and mechanisms by which cancerassociated fibroblasts are activated may be an emerging novel therapeutic strategy for breast cancer.

High mobility group box 1 (HMGB1) or amphoterin is a chromatin-associated nuclear protein. It has also been recognized as an extracellular "damage-associated molecular pattern" (DAMP) molecule, which has been detected in several diseases including cancer [20]. HMGB1 can be produced by both tumor cells and stromal cells and is released into the extracellular environment from stressed and dying cells [21]. HMGB1 can be released passively from dying tumor cells after chemotherapeutic treatment [22] or following tumor cell lysis by the action of lymphokine-activated killer cells, [23]. In contrast, some studies have reported active secretion of HMGB1 from certain types of cancer $[24,25]$. Several chemotherapeutic agents used in the treatment of breast cancer including cyclophosphamide, methotrexate, paclitaxel [22] and doxorubicin [26] induce HMGB1 release into the tumor microenvironment following cell death. Moreover, radiotherapy has also been shown to induce the release of HMGB1 [26]. Finally, it has been shown that host cells, in particular neutrophils and macrophages, are activated by cytokines as part of an innate immune response to cancer cells and actively secrete HMGB1 [27].

Interestingly, factors diffusing from stromal fibroblasts have recently been shown to up-regulate intracellular HMGB1 in lung cancer cells [28]. HMGB1 may then be released from cancer cells during radiotherapy or chemotherapy and act upon surviving cancer cells to promote regrowth and metastasis [29]. Hence we hypothesized that stromal fibroblasts in breast cancer may also play a similar role in chemoresistance through the up-regulation of HMGB1 in cancer cells during chemotherapy-mediated cell death. This study aimed to explore the effect of secreted substances from breast cancer-associated fibroblasts (BCFs) on HMGB1 expression in breast cancer cells and the potential of extracellular HMGB1 to influence chemosensitivity.

\section{Methods}

\section{Breast cancer cell culture}

The human breast cancer cell line MDA-MB-231 was obtained from ATCC-LGC (\#HTB-26, Middlesex, UK). Cells were cultured in DMEM (Gibco, Grand Island, NY, USA) supplemented with $10 \%$ fetal bovine serum (FBS; Gibco), $100 \mathrm{U} / \mathrm{ml}$ penicillin, $100 \mu \mathrm{g} / \mathrm{ml}$ streptomycin (Gibco), and anti-fungal agent. Cells were cultured in a $5 \% \mathrm{CO}_{2}$ in air incubator at $37^{\circ} \mathrm{C}$ and passaged by $0.25 \%$ trypsin-EDTA when they reached confluence. Cells of more than $90 \%$ viability evaluated by trypan blue dye exclusion were used in further experiments.

\section{Primary cultures of human fibroblasts}

Primary cultures of breast cancer-associated fibroblasts (BCFs) were isolated from patients who underwent surgery at Siriraj Hospital, Mahidol University, Bangkok, and non-tumor-associated fibroblasts (NTFs) were isolated in each case from adjacent uninvolved breast tissue. The protocol for tissue collection was approved by the Siriraj Institutional Review Board (si498/2010) and informed consent was obtained from each of the six patients enrolled for this study. All breast cancers were of the hormone receptor positive luminal subtype. Briefly, sterile fresh surgical tissue was placed on ice in DMEM/F12 (Gibco) supplemented with 10X penicillin-streptomycin (1,000 $\mathrm{U} / \mathrm{ml}$ penicillin and $1,000 \mu \mathrm{g} / \mathrm{ml}$ streptomycin) (Gibco). Tissues were washed 2 to 3 times by $1 \mathrm{X}$ phosphate 
buffered saline (PBS) to remove blood contamination. Tissues were then minced finely using a sterile surgical blade followed by enzymatic dissociation in collagenase type $1 \mathrm{~A}$ $(1,140 \mathrm{U} / \mathrm{ml})$ (Sigma-Aldrich, St. Louis, MO, USA) diluted in DMEM/F12 supplemented with $10 \%$ FBS for $2 \mathrm{~h}$ at $37^{\circ} \mathrm{C}$ with agitation every $20 \mathrm{~min}$. Next, tissues were digested in $0.05 \%$ trypsin-EDTA (Gibco) in serum-free DMEM/F12 for $10 \mathrm{~min}$. The digestion solution was removed and fragments were washed with DMEM/F12 containing no FBS. The cell suspension was sequentially filtered through $100 \mu \mathrm{m}$ and $70 \mu \mathrm{m}$ nylon meshes (BD Biosciences, San Jose, CA, USA) and centrifuged at 2,000 xg for $5 \mathrm{~min}$. The cell pellet was resuspended in complete DMEM/F12 media and cultured in a $25 \mathrm{~cm}^{2}$ culture flask (Corning, NY, USA). Cells isolated from tissue samples were incubated in DMEM/F12 media containing 10\% FBS for 10-14 days to allow attachment and the formation of colonies; these primary cultures were designated as passage 0 . All cultures were kept in a humidified incubator with $5 \% \mathrm{CO}_{2}$ in air at $37^{\circ} \mathrm{C}$. Cells were subcultured when $80 \%$ confluent, banked and used for characterization and experimental studies at passages $5-13$.

\section{Immunocytochemistry of BCFs and NTFs}

To discriminate BCFs and NTFs from cancer cells, immunohistochemical staining for epithelial CK19 and mesenchymal ASMA markers were performed. The breast cancer cell line, MDA-MB-231 was used as a positive control for CK19 detection. In brief, around 4,000 cells were plated into each well of a 96-well plate and cultured for 24-h to allowed for cell adhesion. Cells were then fixed with $4 \%$ paraformaldehyde. Non-specific binding was blocked by incubating cells with 1\% BSA in 1X PBS for ASMA detection or 5\% FBS in 1X PBS for CK19 detection. Mouse antihuman CK19 antibody (SC-6278; 1:100 dilution, Santa Cruz Biotechnology Inc., Dallas, TX, USA) or mouse anti-human ASMA antibody (A5228, 1:200 dilution, Sigma-Aldrich) was added for $3 \mathrm{~h}$ at room temperature. A blocking reagent was used as the negative control in place of the primary antibody. After washing with $1 \mathrm{X}$ PBS, goat anti-mouse IgG-Cy3 antibody (\#115-166-071, 1:2,000, Jackson ImmunoResearch Laboratories Inc, West Grove, PA, USA) was applied for $1 \mathrm{~h}$ at RT. The signals were detected by fluorescence microscopy.

\section{Collection of fibroblast conditioned-media}

Cultures of BCF and NTF were grown in $75-\mathrm{cm}^{2}$ flasks to reach $90-95 \%$ confluency in DMEM (containing 10\% FBS) which is a suitable media for MDA-MB-231 cells. The conditioned-media (CM) were collected $24 \mathrm{~h}$ following addition of fresh complete medium and designated as 24-h CM. CMs were centrifuged at 2,000 g for 5 min to remove cell debris and the suspension stored at $-80^{\circ} \mathrm{C}$ or $-20^{\circ} \mathrm{C}$ until use.

\section{Scratch wound tumor cell motility assay}

MDA-MB-231 cells were cultured in a 6-well plate until approximately $90-100 \%$ confluent. A reference line was drawn across the bottom of the plate. A scratch wound was made in the cell monolayer with a sterile $200-\mu l$ pipette tip and the culture was then washed three times with serum-free medium to remove the detached cells. The cells were then treated with BCF-CM, NTF-CM or complete medium as a negative control. The scratch wound indicated by the reference line was imaged at the start of the treatment and $6 \mathrm{~h}$ later. The cell migration efficiency was determined as a percentage of wound healing calculated by the following formula using three different zones for each condition:

$\%$ wound closure $=\frac{(\text { wound width at } 0 \mathrm{~h}-\text { wound width at } 6 \mathrm{~h}) \times 100}{\text { wound width at } 0 \mathrm{~h}}$

\section{Real time PCR for HMGB1 mRNA detection}

Total RNA was extracted from MDA-MB-231 breast cancer cells using the PerfectPure RNA Cultured Cell Kit (5 Prime; Gaithersburg, MD, USA) as per the manufacturer's instructions. The OD260/280 and OD260/230 were measured to ensure the quality of extracted RNA. Complementary DNA was synthesized from $1 \mu \mathrm{g}$ of total RNA using the SuperScript ${ }^{\mathrm{Tm}}$ III First-Strand Synthesis System for RT-PCR (M-MLV) (Invitrogen, Carlsbad, CA, USA) according to the manufacturer's instructions. Expression levels of $H M G B 1$ were determined by SYBR Green-based real time PCR (Roche Applied Sciences, Indianapolis, IN, USA) in a Light Cycler 480 II machine (Roche Applied Sciences). Optimal primers were designed using the nucleotide database in PubMed and Primer 3 software. Sequences of primers were: $H M G B 1$ (NM_002128.4): forward primer: 5'-CACTGGGCGAC TCTGTGCCTCG-3', reverse primer: 5'-CGGGCCTT GTCCGCTTTT-GCCA-3'. $\beta$-actin (ACTB) served as an internal control to adjust the amount of starting cDNA. The expression of each gene in breast cancer cells was calculated by the $2^{-\triangle C_{\mathrm{p}}}$ equation. In this case, $\Delta C_{\mathrm{p}}=\mathrm{C}_{\mathrm{p}}(H M G B 1)-\mathrm{C}_{\mathrm{p}}(A C T B)$. The expression of $H M G B 1$ in breast cancer cells treated with fibroblast CM or doxorubicin (Dox) (Pfizer, Perth Pty Ltd, Bentley WA, Australia) compared with that in untreated control cells was calculated by the $2^{-\Delta \Delta C \mathrm{p}}$ equation. In this case, $\Delta C_{\mathrm{p}}=\mathrm{C}_{\mathrm{p}}(H M G B 1)-\mathrm{C}_{\mathrm{p}}(A C T B)$ and $\Delta \Delta C \mathrm{p}=\Delta C_{\mathrm{p}}$ (treated cells) $-\Delta C_{\mathrm{p}}$ (control cells).

\section{Western blot analysis}

MDA-MB-231 breast cancer cells were treated with BCF-CM or NTF-CM for $48 \mathrm{hr}$. Cell suspensions were centrifuged at 2,000 $\times \mathrm{g}$ for $5 \mathrm{~min}$ in a refrigerated centrifuge. The cell pellets were collected and rinsed in cold 1X PBS twice before lysis in $1 \mathrm{X}$ sample buffer containing 
50 mM Tris- $-\mathrm{HCl}$ pH 6.8, 2\% (w/v) SDS, 10\% (v/v) glycerol, $5 \%(\mathrm{v} / \mathrm{v}) \beta$-mercaptoethanol and $0.05 \%(\mathrm{w} / \mathrm{v})$ bromophenol blue. Cell lysates were boiled for $10 \mathrm{~min}$ and centrifuged at 10,000 rpm for $1 \mathrm{~min}$ to remove undissolved proteins and cell debris. Cell extracts were then separated by 10\% SDS-PAGE and transferred onto PVDF membranes (GE Healthcare, Buckinghamshire, UK). Membranes were blocked in 5\% skimmed milk containing TBST (TBS containing $0.1 \%$ Tween 20 ) for $1 \mathrm{~h}$ at room temperature. Membranes were then washed 3 times with $1 \mathrm{X}$ TBST and incubated with 1:1,000 rabbit anti-human HMGB1 (ab18256, Abcam, Cambridge, CB4 OFL, UK) at $4^{\circ} \mathrm{C}$ overnight. After washing, membranes were incubated with 1:2,000 goat anti-rabbit IgG-HRP (Abcam) at room temperature for $1 \mathrm{~h}$. The blots were visualized by enhanced chemiluminescence (Thermo Scientific, Rockford, IL, USA). Using 1:10,000 anti- $\beta$-actin antibody (sc47778, Santa Cruz Biotechnology Inc.) or 1:10,000 anti- $\beta$-actin antibody (ab8226, Abcam) with the suitable HRP conjugated secondary antibody, $\beta$-actin protein levels were used as an internal control to confirm equal protein loading. $\beta$-actin normalized HMGB1 levels in breast cancer cells without any CM treatment were used as controls.

The same procedure was used for the measurement of extracellular HMGB1 except for the process of sample collection. To measure the amount of HMGB1 released from cells, the media from cells stimulated with either BCF-CM or NTF-CM were collected and concentrated using a $10 \mathrm{kDa}$ cut-off Vivaspin concentrator (Sartorius Stedim Biotech, Goettingen, Germany) at 3,500 ×g. Protein concentration was determined by a Coomassie Plus (Thermo Scientific) assay kit. The same amount of total protein was loaded into SDS-PAGE gels and the procedure for detection of HMGB1 above.

For LC3B autophagy protein detection, cells were treated with $100 \mathrm{ng} / \mathrm{ml}$ human rHMGB1 (\#1690-HMB050, R\&D Systems, Minneapolis, MN, USA) with or without anti-HMGB1 neutralizing antibody (H00003146M08, Novus, Littleton, CO, USA) before exposure to Dox for $24 \mathrm{~h}$. Cells were harvested and total proteins were separated and blotted on to the membrane as described above. The rabbit anti-human LC3B (\#2775, Cell Signaling Technology, Danvers, MA, USA) was then incubated at 1:2,000 dilution with the membranes at $4^{\circ} \mathrm{C}$ overnight followed by goat anti-rabbit IgG-HRP (\#7044, Cell Signaling Technology; 1:1,200 dilution) at room temperature for $1 \mathrm{~h}$. The blots were visualized as described previously.

\section{Treatment of MDA-MB-231 breast cancer cells with} doxorubicin or conditioned-media

MDA-MB-231 breast cancer cells were cultured in 6-well plates $\left(3 \times 10^{5} /\right.$ well $)$ for $48 \mathrm{~h}$, then the growth medium was removed and the cells washed thoroughly with PBS.
CM from either BCF or NTF was added to the cells which were incubated for a further $48 \mathrm{~h}$ at $37^{\circ} \mathrm{C}$ in a $5 \% \mathrm{CO}_{2}$ in air incubator. Negative controls were cultured in parallel in DMEM plus $10 \%$ FBS. Cells were then harvested to determine the level of intracellular HMGB1 expression by real time PCR and Western blot analysis. At the same time, the culture media were also collected to investigate the level of extracellular HMGB1. Similarly, 1 and $5 \mu \mathrm{M}$ doxorubicin Dox (Pfizer) was used to treat MDA-MB-231 breast cancer cells for $48 \mathrm{~h}$. Dox-treated cells were harvested to determine the level of intracellular HMGB1 by real time PCR and the culture medium was also collected to investigate the level of extracellular HMGB1. In addition, cancer cells with or without pre-treatment with fibroblast CMs were then exposed to Dox for $48 \mathrm{~h}$ to induce cell death and the release of HMGB1. Cell viability was checked by trypan blue exclusion and the levels of HMGB1 were determined by Western blot analysis as above.

\section{Response of breast cancer cells treated with recombinant HMGB1 to Doxorubicin}

MDA-MB-231 cells were seeded into 96-well plates at 6,000 cells per well and cultured overnight in DMEM + $0.1 \%$ FBS. Cells in triplicate wells were then treated with $100 \mathrm{ng} / \mathrm{ml} \mathrm{rHMGB1}$ (R\&D Systems) in the presence or absence of $10 \mathrm{mg} / \mathrm{ml}$ HMGB1-neutralizing antibody (Novus) and then $5 \mu \mathrm{M}$ Dox or vehicle. Cell viability was measured $24 \mathrm{~h}$ later by trypan blue exclusion.

\section{Effect of CM on Dox sensitivity of MB-231 breast cancer cells}

MDA-MB-231 cells were plated at a density of 6,000 cells/well in 96-well plates. These cells were treated for $24 \mathrm{~h}$ with CM collected from MDA-MB-231 cells exposed to $5 \mu \mathrm{M}$ Dox (for $48 \mathrm{~h}$ ), designated as 'dead cancer-CM', with or without anti-HMGB1-neutralizing antibody (10 $\mathrm{mg} / \mathrm{ml}$ ) or isotype-matched control IgG (X0943, Dako, Agilent Technologies, Glostrup, Denmark). Cell viability after exposure to $5 \mu \mathrm{M}$ Dox was analyzed by erythrosine $\mathrm{B}$ dye exclusion and compared with control untreated cells. Three independent experiments were performed.

\section{Statistical analysis}

The values are expressed as mean \pm SD. Statistical significance was determined by Student's t-test. A p-value of equal to or less than 0.05 was defined as statistically significant.

\section{Results}

Characterization of primary cultures of BCFs and NTFs BCFs and NTFs were characterized by their expression of the mesenchymal marker, ASMA, and absence of the 
epithelial marker, CK19. Immunocytochemical staining revealed that all cancer-associated and 'normal' breast fibroblasts from six different patients were negative for CK19 compared with the positive control MDA-MB-231 breast cancer cells (Figure 1) and were positive for ASMA. Thus we confirmed that both BCFs and NTFs were mesenchymally-derived cells with no epithelial cell contamination.

To ensure that the BCFs were activated and capable of promoting malignant potential, the effects of $\mathrm{CM}$ on MDA-MB-231 breast cancer cell migration were tested. The results indicated that the BCF-CM promoted cancer cell migration to a significantly greater degree than NTF-CM (Figure 2). Indeed, NTF-CM had a minimal effect compared with untreated control cells.
Increased expression of HMGB1 in breast cancer cells treated with fibroblast-derived $\mathrm{CM}$

BCF-CM significantly induced intracellular HMGB1 protein expression in MDA-MB-231 breast cancer cells as detected by Western blot analysis at all time points tested (Figure 3). The effect was time-dependent and since the greatest differential induction (BCF-CM vs NTF-CM) was observed at $48 \mathrm{~h}$, this time period was selected for further studies. As a further quality control, the CMs of BCF and NTF isolated from the same patient were used to treat MDA-MB-231 cells and HMGB1 gene expression was analyzed by real time PCR. The results showed that BCF-CM induced HMGB1 mRNA to a significantly greater degree than NTF-CM (Figure 4A). Western blot analysis confirmed that the protein levels

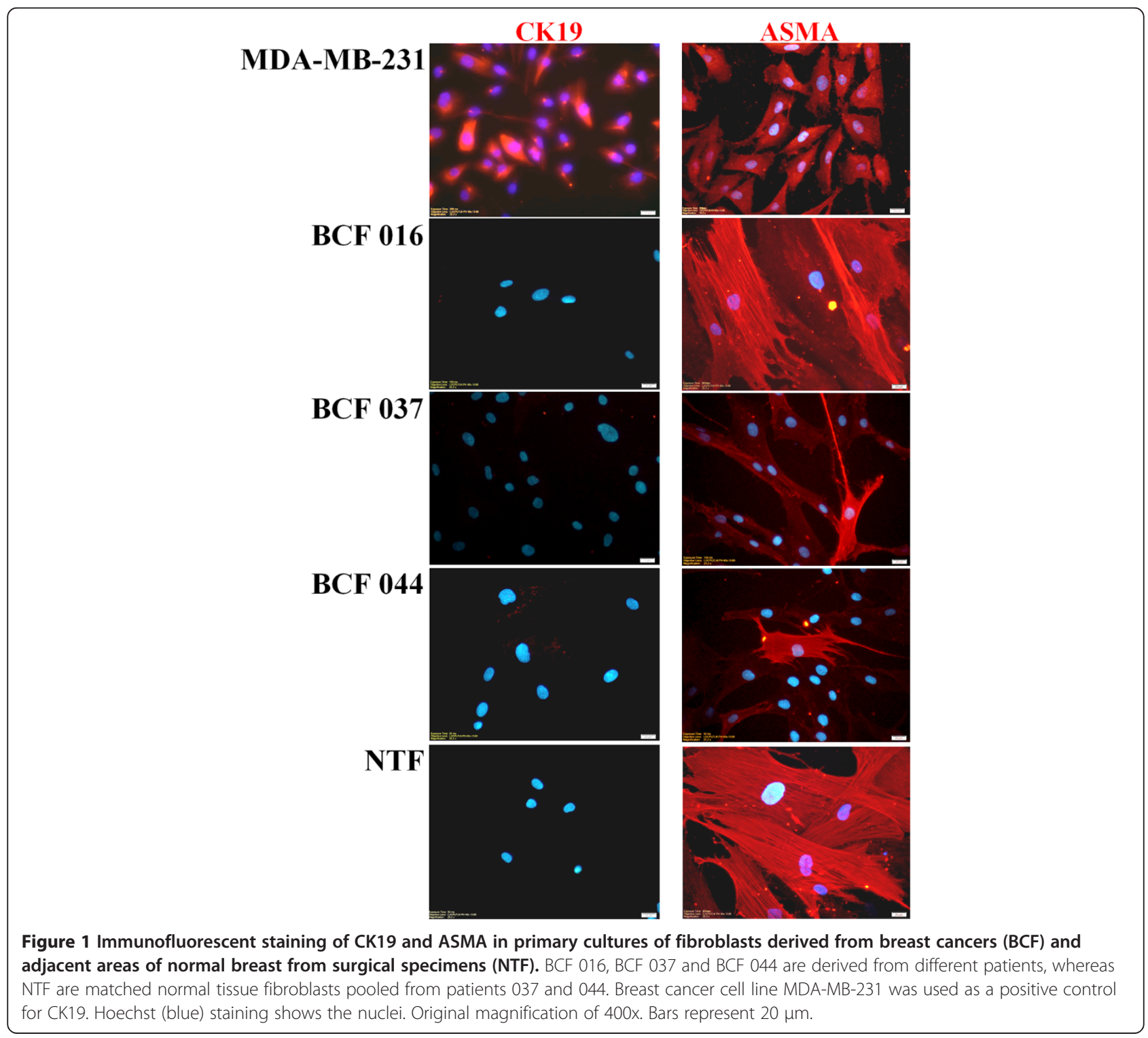



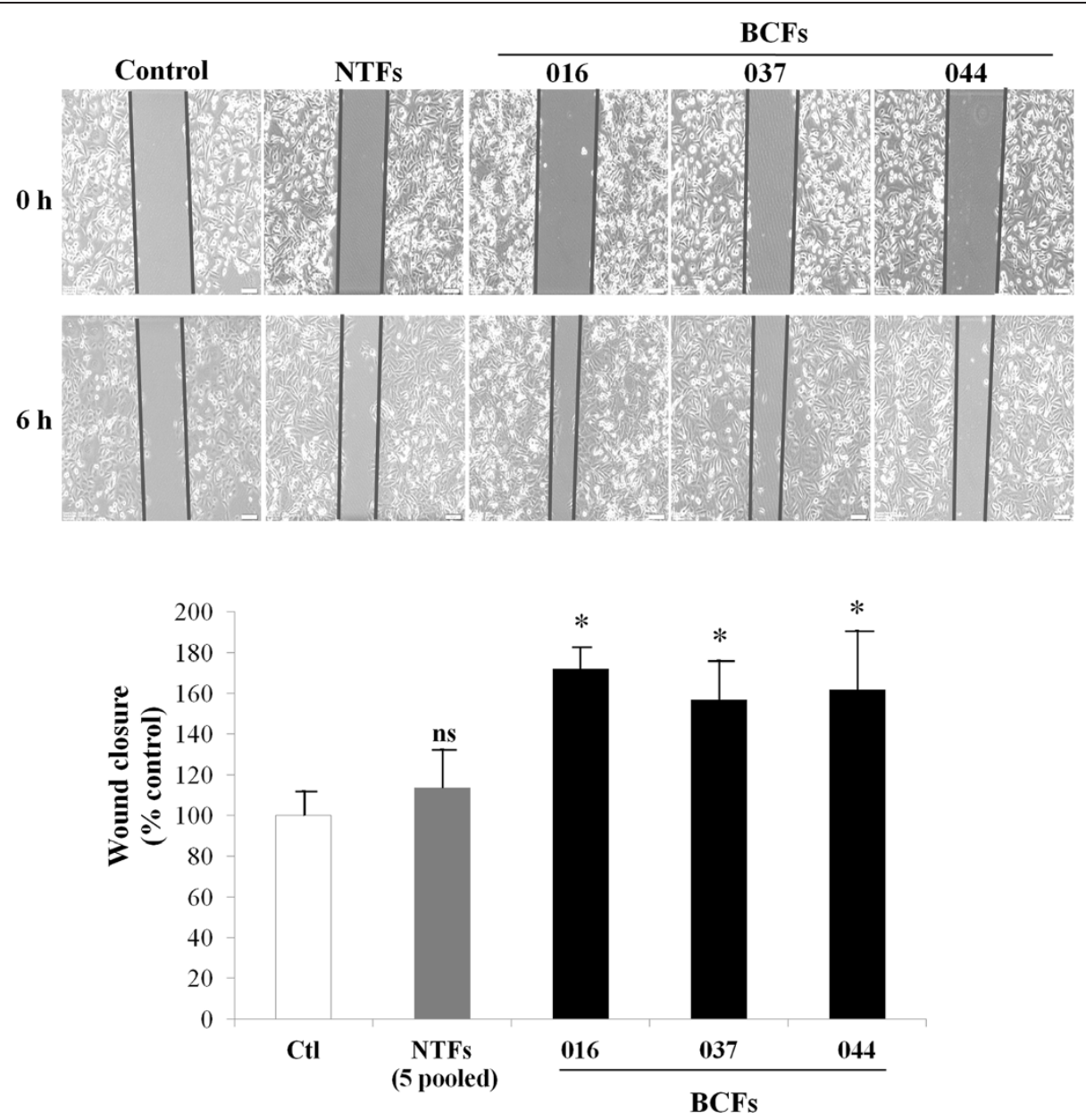

Figure 2 BCF-CMs enhance MDA-MD-231 cell migration. MDA-MB-231 breast cancer cells were exposed to 3 different BCF-CMs and pooled samples of 5 NTF-CMs and a scratch wound motility assay was performed over $6 \mathrm{~h}$ to measure the ability of CM to induce cancer cell migration. Bar graphs represent mean \pm SD of two independent experiments. The migration of cells in control fresh media (Ctl) was set at $100 \%{ }^{*}=$ p-value of less than 0.05 compared to the migration of cancer cells under control conditions. ns = not significance.

of HMGB1 induced by BCF-CM were statistically significantly higher than those induced by patient-matched NTF-CM (Figure 4B). In addition, HMGB1 protein levels in MDA-MB-231 cells treated with BCF-CMs from different patients were consistently significantly higher than those treated with NTF-CMs.

\section{Cell death induced by Dox promotes expression and release of HMGB1}

Doxorubicin is commonly used in breast cancer treatment and our results using real time PCR showed that this drug could induce intracellular HMGB1 expression in MDA-MB-231 cells in a concentration-dependent manner (Figure 5A). The maximal level of HMGB1 was induced with $5 \mu \mathrm{M}$ which was statistically significantly different from untreated controls. Moreover, cancer cells killed by Dox exposure released HMGB1 into the culture media and the level was again increased in a concentrationdependent manner (Figure 5B).
BCF-CM-pretreated cancer cell cultures showed less cell death in response to Dox than cells pre-treated with NTF-CM (Figure 5C). In a second study, we found that BCF-CM treated cells also released more HMGB1 than those pre-treated with NTF-CM when treated with equitoxic concentrations of Dox (80\% cell death) (Figure 5D). No HMGB1 was detected in the culture media when cell viability was greater than $95 \%$ but in contrast, Doxinduced release of HMGB1 was related to the degree of cell death (data not shown).

Recombinant HMGB1 alters Dox sensitivity via autophagy MDA-MB-231 cells exposed to Dox together with rHMGB1 showed statistically significantly higher viability than those treated with Dox alone (Figure 6A). This effect was reversed by the addition of an HMGB1 neutralizing antibody. The fact that LC3B-I converts to LC3B-II and levels of LC3B-II increase over time suggests that 

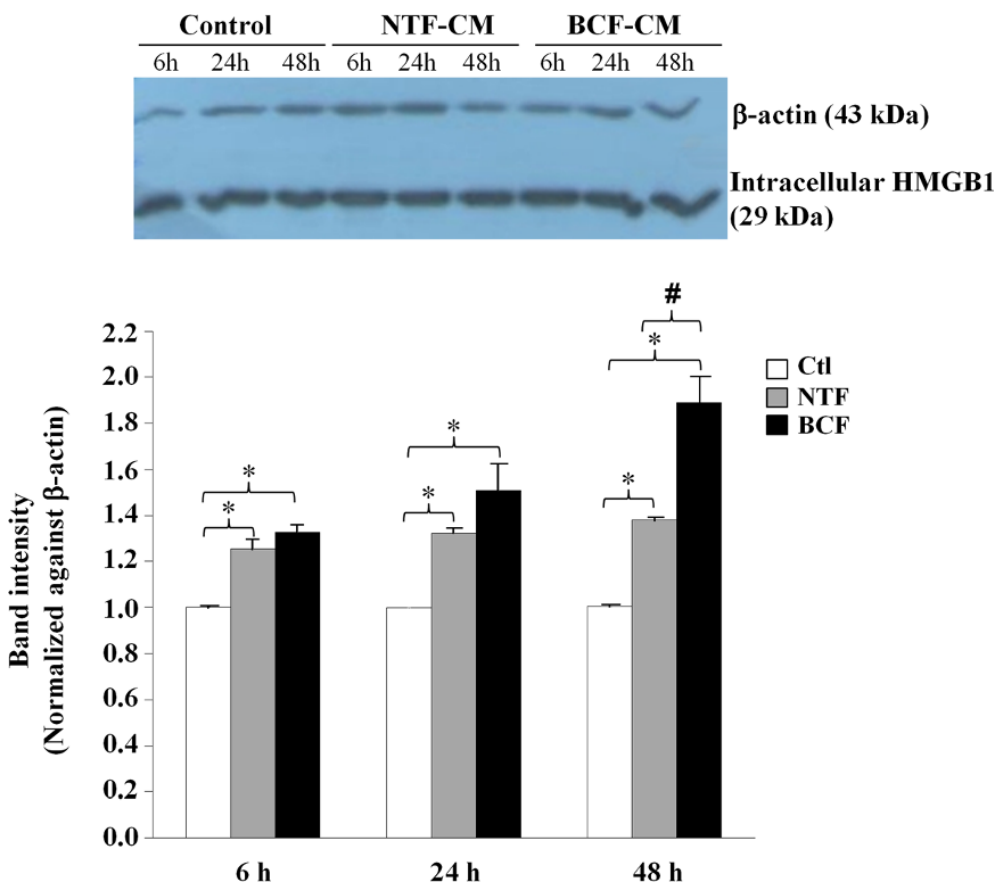

Figure 3 Western blot analysis of intracellular HMGB1 in MDA-MB-231 human breast cancer cells treated with fibroblast CMs (BCF 044 and NTF $\mathbf{0 4 4}$ ) for $\mathbf{6 , 2 4}$, and $48 \mathrm{~h}$. Cancer cells cultured in fresh medium were used as a negative control. The intensity of each HMGB1 band is shown after normalization against the $\beta$-actin internal loading control protein. Bar graphs represent mean \pm SD of two independent experiments. * = p-value of less than 0.05 comparing HMGB1 levels in the CM-treated cells with controls at each time point; \# = p-value of less than 0.05 comparing HMGB1 levels in BCF-CM-treated cells with NTF-CM treatment.

autophagy occurs in MDA-MB-231 cells treated with rHMGB1 (Figure 6B).

\section{Dead cancer cell CM attenuates the effects of Dox on MDA-MB-231 breast cancer cell viability in part via HMGB1}

Dead cancer-CM, (shown to increase the level of extracellular HMGB1; Figure 5B) also increased the survival of MDA-MB-231 cells during subsequent Dox treatment (Figure 6C) and this effect was reversed by an HMGB1 neutralizing antibody (**p-value $=0.006)$. The blocking antibody also showed a small but significant reduction in cell viability in the absence of CM ( $p$-value $=0.017$ ).

\section{Discussion}

One of the main reasons for treatment failure in breast cancer is acquired drug resistance. The interaction of tumor cells with their microenvironment has been frequently reported to influence cancer progression and drug resistance $[5,7,30]$. Tumor-associated stromal cells have been shown to protect tumor cells from cell death and the cytotoxic effects of chemotherapeutic drugs $[31,32]$. Recently, the impact of cancer-associated fibroblasts on the expression and localization of HMGB1 in lung cancer cells has been demonstrated to operate via the release of diffusible factors from fibroblasts [28]. The extracellular HMGB1 protein behaves as a cytokine, promotes inflammation and participates in the pathogenesis of several disorders in peripheral organs. Extracellular HMGB1 has potential impact in the induction of drug resistance and has been proposed as an immunotherapeutic target to modulate chemotherapeutic responses [22].

Activated fibroblasts in breast cancer tissues have been identified in several reports $[11,15]$. In invasive ductal carcinoma, metastatic ability is closely related to the proliferation of fibroblasts [12]. To clearly understand the biological function of fibroblasts in cancer tissues, primary cultures of human fibroblasts are critical. The identity of primary NTFs and BCFs was confirmed here by ASMA positivity [33,34]. All breast cancer tissues used for isolation of primary cultures of fibroblasts in this study were of luminal subtype and positive for estrogen receptor and/or progesterone receptor. The absence of the CK19 epithelial marker was taken as an indication that the fibroblasts were not cancer cells that had undergone an epithelial-to-mesenchymal transition (EMT). This is supported by the evidence that EMT is most common in basal-like breast cancers [35] and loss of CK19 is rare in hormone receptor-positive breast cancer tissues [36]. ASMA can be used to indicate that the fibroblasts are myofibroblasts but cannot determine their tumor-promoting potential. Cancer-associated fibroblasts 


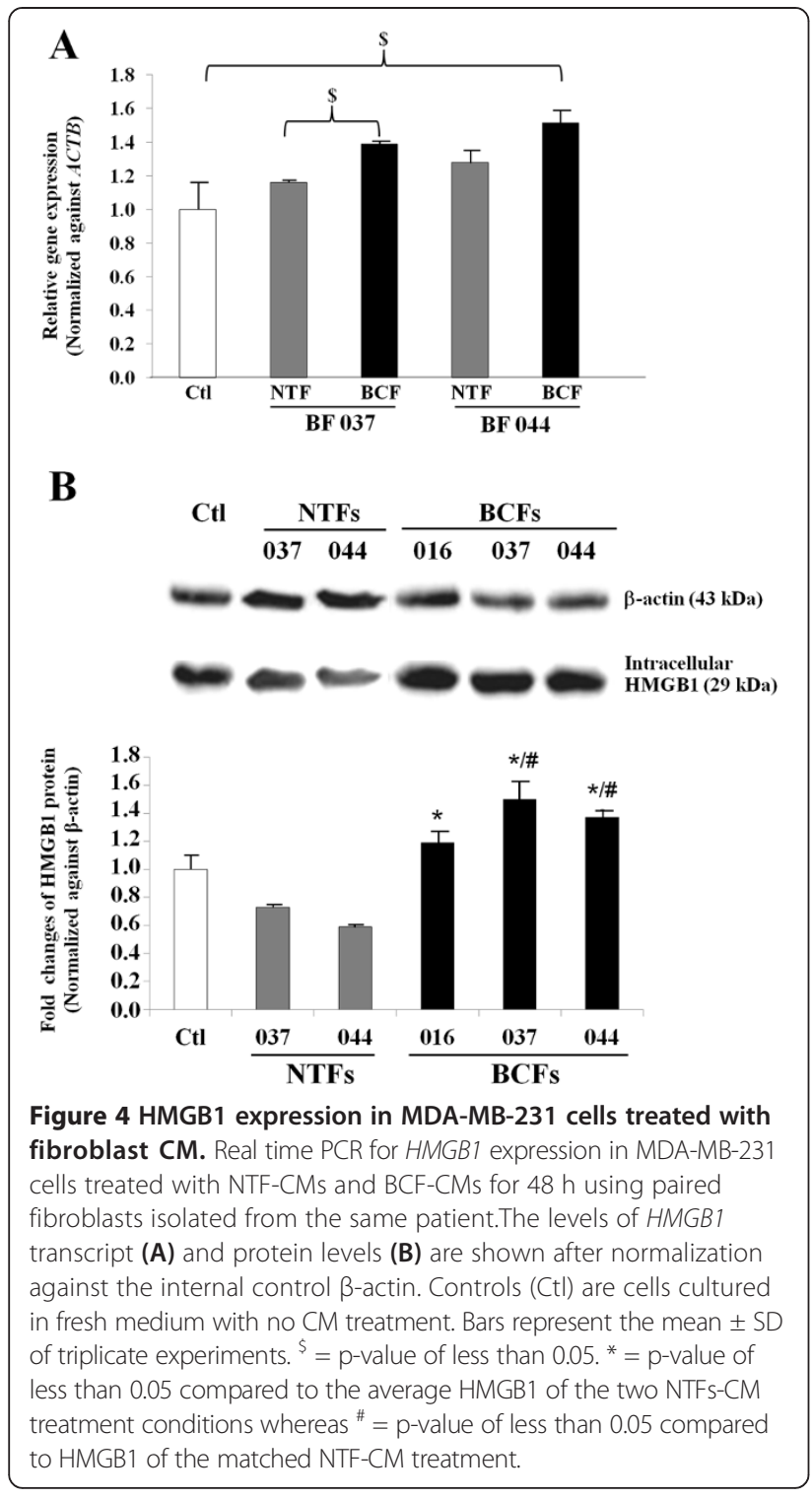

have been recognized for their ability to secrete protumorigenic molecules and to promote cancer progression $[8,37]$. We used the ability of the BCF-CM to promote breast cancer motility in a scratch wound assay as an indicator of their activated phenotype.

The present study confirmed the effect of fibroblastderived substances in enhancing HMGB1 expression in human breast cancer cells. Primary cultures of fibroblasts isolated directly from breast cancer tissues (and with patient-matched control cells) were used in preference to established fibroblast cell lines for greater clinical relevance. Cancer cells exposed to fibroblast CM showed increased survival in response to a standard chemotherapeutic agent, doxorubicin. This protective effect correlated with the increased level of HMGB1 released from the cells, was mimicked by recombinant HMGB1 and reversed by the HMGB1 blocking antibody. These observations suggest that cancer-associated fibroblasts should be considered as a possible therapeutic target to attenuate acquired chemoresistance in breast cancer patients via activation of HMGB1.

Interestingly, the $\mathrm{CM}$ derived from BCFs induced the production of HMGB1 in cancer cells in a timedependent manner to a significantly greater degree than the CM from NTFs derived from adjacent non-involved breast tissue in the same patient. These results are in agreement with a previous report using lung fibroblast CMs to activate HMGB1 production in lung cancer cells [28]. From this study, the small amount of actively released HMGB1 detected under control conditions (with no diffusible factors from fibroblasts) was ascribed to necrotic cell death in vitro.

It is well known that monocytes and macrophages can actively secrete HMGB1 in response to various stress stimuli [27]. Although some cancer cells have the ability to secrete HMGB1 into the culture media, these are limited and include colon cancer and malignant mesothelioma [24,25,38]. Alternatively, HMGB1 release can be induced by hypoxia [39] or inflammatory cytokines [40]. In breast cancer tissues investigated by immunohistochemistry, it is possible that phosphorylated HMGB1 may reside in the cytoplasm which corresponds to our observations of increased cytoplasmic HMGB1 in breast cancer tissues (data not shown).

HMGB1 is overexpressed in many types of cancer [41-45] including breast cancer [46-48]. In addition to this intrinsic expression, breast cancer cells can be stimulated by factors released from activated fibroblasts to increase their expression of HMGB1. When these cancer cells die after cytotoxic treatment, extracellular HMGB1 is detected in proportion to the levels of intracellular HMGB1. In the present study, MDA-MB-231 breast cancer cells were induced by BCF-CMs (or by Dox) to express high levels of HMGB1.When cell death was induced, HMGB1 could be subsequently released. It can be hypothesized that HMGB1 could then act upon surrounding cancer cells to induce a degree of resistance to chemotherapeutic agents. In support of our findings, extracellular HMGB1 has been shown by Luo et al. to stimulate the regrowth and metastasis of cancer cells that survived prior chemotherapy [29].

Using 'dead cancer-CM', our results indicate that HMGB1 may be one component released by dying cells that can influence the response of other cancer cells to Dox. However, the viability of breast cancer cells could not be completely rescued by an HMGB1 neutralizing antibody, implying that other substances released from dead cancer cells may be responsible for Dox resistance. Extracellular HMGB1 binds to the 'receptor for advanced glycation end 


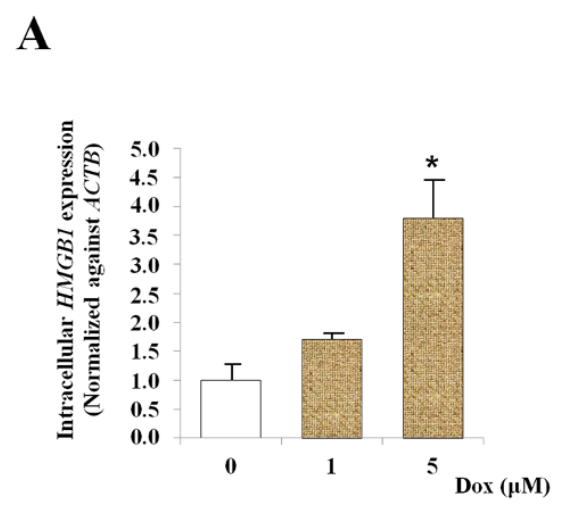

C
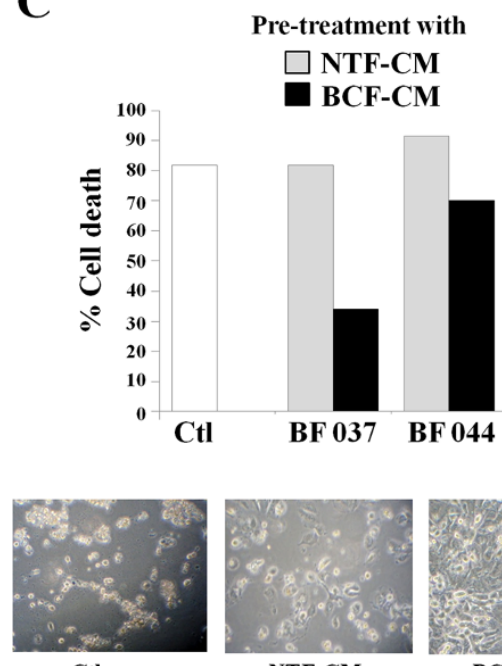

Ctl

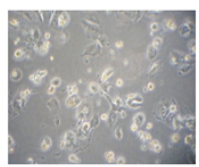

NTF-CM

Pre-treatment with
B
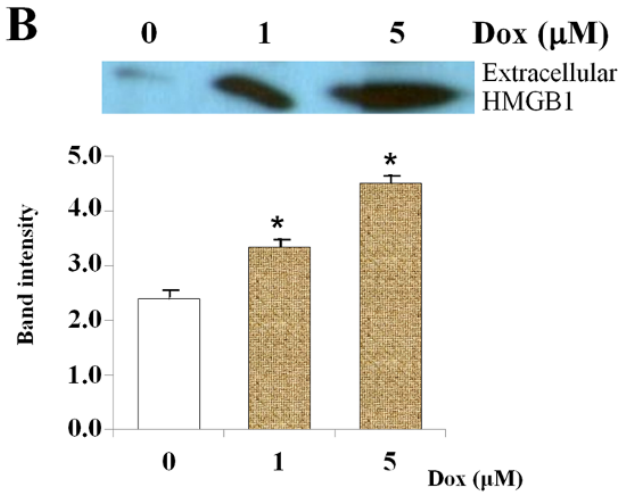

D
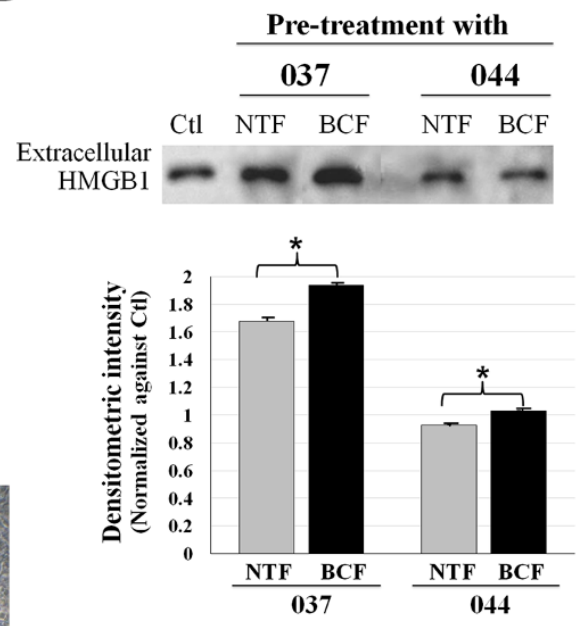

Figure 5 Dox-induced HMGB1 in MDA-MB-231 cells. (A) Intracellular HMGB1 expression was measured by real time PCR. Bars represent mean \pm SD of $H M G B 1$ expression level normalized against $A C T B$ and relative to no drug treatment. Three independent experiments were performed. (B) Extracellular HMGB1 protein was detected by Western blot analysis in the culture media from cells treated with different concentrations of Dox for 48 h. (A and B) ${ }^{*} \mathrm{p}$-value of less than 0.05 compared to the controls without Dox treatment. (C) BCF-CM induced resistance to Dox-mediated cell death in MDA-MB-231 breast cancer cells. Bars represent \% cell death of each pre-treatment condition and the images show corresponding cell density. (D) Culture media from each condition in (C) were measured for extracellular HMGB1 by Western blot analysis. Equal amounts of proteins were loaded. Bars represent the mean band intensity $( \pm \mathrm{SD})$ measured by densitometry. The band intensity of control cultures without CM pre-treatment (Ctl) was set as $1 .{ }^{*} \mathrm{p}$-value of less than 0.05 .

products' (RAGE), in cancers but not normal tissues [49]. However, HMGB1 can promote 3T3 fibroblast wound healing by inducing cell proliferation and migration, and this effect occurs through the activation of the RAGE/ MEK/ERK pathway [50]. HMGB1 caused concentration and time-dependent increases of IL- 6 production via RAGE, c-Src, Akt, p65, and NF-kB signaling pathways [51]. Although the pathways activated by extracellular HMGB1 in breast cancer cells have not been identified, they may lead to the induction of cancer progression and drug resistance. The ability of released HMGB1 to trigger drug resistance in cancer cells is reportedly due to autophagy $[52,53]$. In addition, autophagy can also play a role in anthracycline resistance in triple-negative breast cancer (TNBC) [54]. This is supported by our findings that HMGB1 was linked to autophagy and Dox resistance in TNBC MDA-MB-231 cells.

The data reported here indicate the potential of extracellular HMGB1 released from breast cancer cells to exert a paracrine effect on surviving cancer cells enabling them to resist Dox therapy. An anti-HMGB1 antibody or specific inhibitor (i.e. glycyrrhizin) [55] or targeting its proposed receptors (RAGE and the toll-like receptor 4, TLR4) on cancer cells may prevent or inhibit the development of drug resistance. In contrast, there is the evidence that chemotherapeutic drug-induced HMGB1 can mediate 


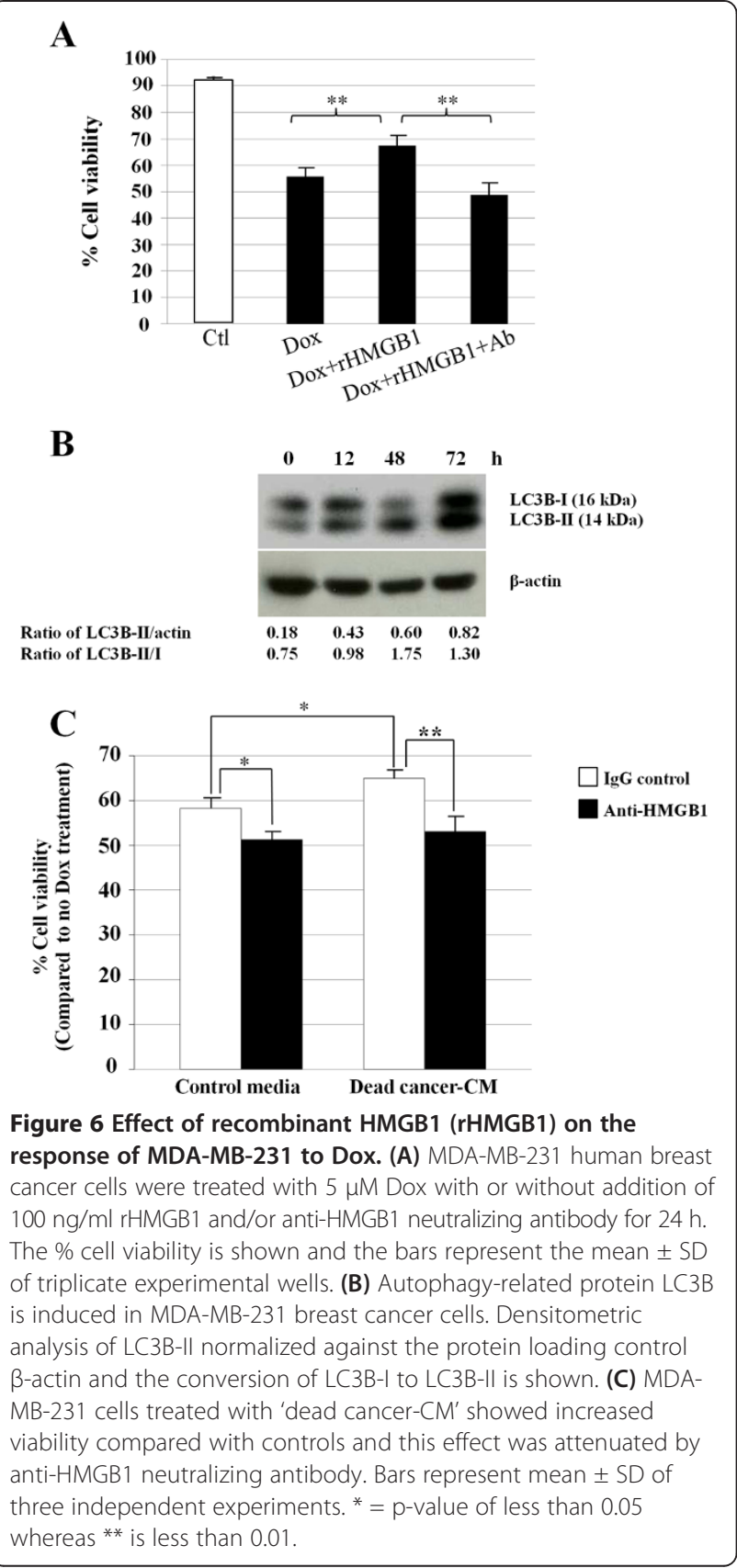

the activation of innate immunity and tumor clearance [56]. Thus caution must be exercised, given the potential positive and negative aspects of HMGB1 expression at different phases of tumor development and during treatment.

\section{Conclusions}

The findings reported here highlight the potential of cancer-stromal fibroblast interactions to drive chemoresistance in breast cancer in part as a result of fibroblastinduced HMGB1 production and release into the tumor microenvironment with paracrine effects on neighboring cancer cells (Figure 7). To support this hypothesis,

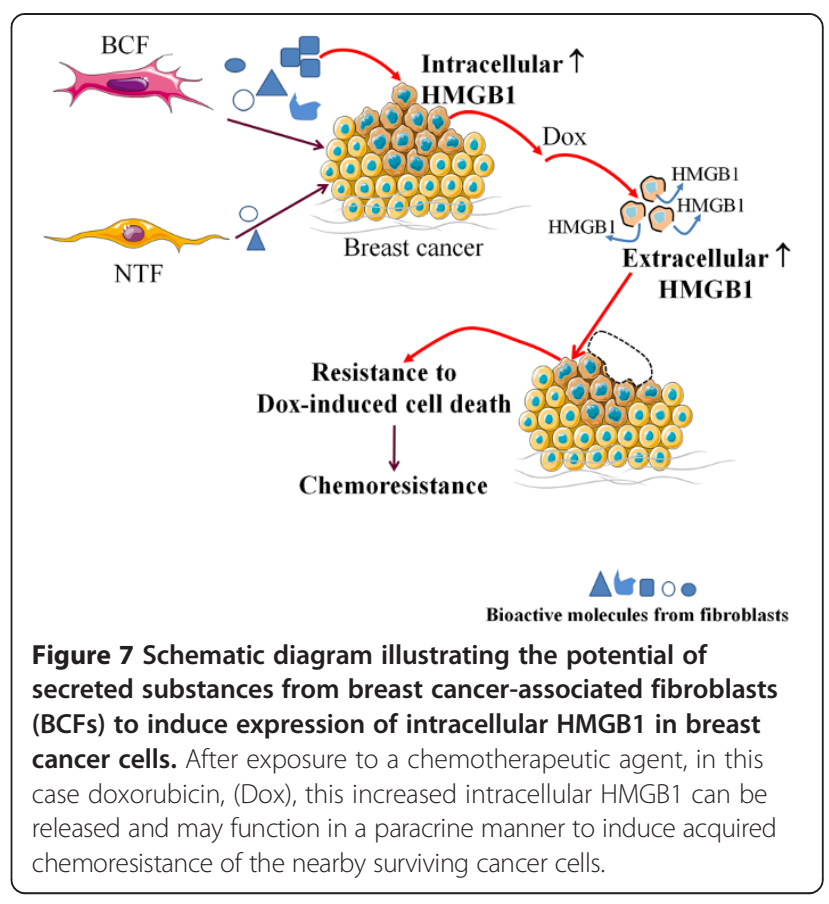

circulating HMGB1 levels could be tested as a predictor of responses to neo-adjuvant chemotherapy in breast cancer patients [57]. High levels of serum HMGB1 in patients have been correlated with drug resistance whereas low HMGB1 indicated sensitivity. Targeting cancer-associated fibroblasts which have more genetic stability than cancer cells is an alternative therapeutic approach [30] to interrupt the cycle of fibroblast-induced HMGB1 in mediating acquired chemoresistance.

\section{Abbreviations}

ASMA: Alpha smooth muscle actin; HMGB1: High mobility group box 1; CK: Cytokeratin; CM: Conditioned-medium; Dox: Doxorubicin; BCFs: Breast cancer-associated fibroblasts; NTFs: Non-tumor-associated fibroblasts; RAGE: Receptor for advanced glycation end products.

\section{Competing interests}

Authors declare that there is no conflict of interest.

\section{Authors' contributions}

$\mathrm{KA}$ and $\mathrm{CT}$ designed the experiments; $\mathrm{KA}, \mathrm{TI}$ and PT performed the research work; PT and PO prepared the samples. SE designed experiments using anti-HMGB1 neutralizing antibody and edited the final version of the manuscript. CT reviewed the paper, prepared figures, wrote and improved the scientific quality of the manuscript. All authors read and approved the final manuscript.

\section{Acknowledgements}

KA is the student in Graduate Program in Immunology, Department of Immunology, Faculty of Medicine Siriraj Hospital, Mahidol University. This project has been supported by the Mentorship Grant, Mahidol University. KA has been financial supported by Royal Golden Jubilee-Thailand Research Fund (RGJ-TRF : Grant No. PHD/0051/2552). The English editing of this manuscript was kindly performed in part by Professor James A. Will, University of Wisconsin, Madison, WI, USA. Figure 7 was produced using Servier Medical Art on www.servier.com. We thank Dr. Carol Box and Ms. Somaieh Hedayat (ICR) for assistance with the design of experiments described in Figure 6 and for helpful advice and discussions. 


\section{Author details}

${ }^{1}$ Department of Immunology, Faculty of Medicine Siriraj Hospital, Mahidol University, Bangkok 10700, Thailand. ²Department of Surgery, Faculty of Medicine Siriraj Hospital, Mahidol University, Bangkok, Thailand. ${ }^{3}$ Tumor Biology and Metastasis, Cancer Research UK Cancer Therapeutics Unit, The Institute of Cancer Research, Sutton, UK.

\section{Received: 18 April 2014 Accepted: 11 December 2014}

Published: 15 December 2014

\section{References}

1. Jemal A, Bray F, Center MM, Ferlay J, Ward E, Forman D: Global cancer statistics. CA Cancer J Clin 2011, 61(2):69-90.

2. Attasara P, Buasom R: Hospital-based cancer registry 2010. Natl Cancer Inst Thai 2010, 24:1-52

3. Hernandez-Aya LF, Gonzalez-Angulo AM: Adjuvant systemic therapies in breast cancer. Surg Clin North Am 2013, 93(2):473-491.

4. Gonzalez-Angulo AM, Morales-Vasquez F, Hortobagyi GN: Overview of resistance to systemic therapy in patients with breast cancer. Adv Exp Med Biol 2007, 608:1-22.

5. Sebens $\mathrm{S}, \mathrm{Sch}$ afer $\mathrm{H}$ : The tumor stroma as mediator of drug resistance-a potential target to improve cancer therapy? Curr Pharm Biotechnol 2012, 13(11):2259-2272.

6. Franco OE, Shaw AK, Strand DW, Hayward SW: Cancer associated fibroblasts in cancer pathogenesis. Semin Cell Dev Biol 2010, 21(1):33-39.

7. Thibault B, Castells M, Delord JP, Couderc B: Ovarian cancer microenvironment: implications for cancer dissemination and chemoresistance acquisition. Cancer Metastasis Rev 2014, 33(1):17-39.

8. Utispan K, Thuwajit P, Abiko Y, Charngkaew K, Paupairoj A, Chau-in S, Thuwajit C: Gene expression profiling of cholangiocarcinoma-derived fibroblast reveals alterations related to tumor progression and indicates periostin as a poor prognostic marker. Mol Cancer 2010, 9:13.

9. Muerkoster SS, Werbing V, Koch D, Sipos B, Ammerpohl O, Kalthoff H, Tsao MS, Folsch UR, Schafer $\mathrm{H}$ : Role of myofibroblasts in innate chemoresistance of pancreatic carcinoma-epigenetic downregulation of caspases. Int J Cancer 2008, 123(8):1751-1760.

10. Muerkoster S, Wegehenkel K, Arlt A, Witt M, Sipos B, Kruse ML, Sebens T, Kloppel G, Kalthoff H, Folsch UR, Schafer H: Tumor stroma interactions induce chemoresistance in pancreatic ductal carcinoma cells involving increased secretion and paracrine effects of nitric oxide and interleukin1beta. Cancer Res 2004, 64(4):1331-1337.

11. Allinen M, Beroukhim R, Cai L, Brennan C, Lahti-Domenici J, Huang H, Porter D, Hu M, Chin L, Richardson A, Schnitt S, Sellers WR, Polyak K: Molecular characterization of the tumor microenvironment in breast cancer. Cancer Cell 2004, 6(1):17-32.

12. Hasebe T, Sasaki S, Imoto S, Ochiai A: Proliferative activity of intratumoral fibroblasts is closely correlated with lymph node and distant organ metastases of invasive ductal carcinoma of the breast. Am J Pathol 2000, 156(5):1701-1710.

13. Hasebe T, Sasaki S, Imoto S, Ochiai A: Highly proliferative fibroblasts forming fibrotic focus govern metastasis of invasive ductal carcinoma of the breast. Mod Pathol 2001, 14(4):325-337.

14. Busch S, Acar A, Magnusson Y, Gregersson P, Ryden L, Landberg G: TGF-beta receptor type-2 expression in cancer-associated fibroblasts regulates breast cancer cell growth and survival and is a prognostic marker in pre-menopausal breast cancer. Oncogene 2013, doi: 10.1038/onc.2013.527.

15. Mao Y, Keller ET, Garfield DH, Shen K, Wang J: Stromal cells in tumor microenvironment and breast cancer. Cancer Metastasis Rev 2013, 32(1-2):303-315.

16. Farmer $\mathrm{P}$, Bonnefoi $\mathrm{H}$, Anderle $\mathrm{P}$, Cameron $\mathrm{D}$, Wirapati $\mathrm{P}$, Becette $\mathrm{V}$, Andre $\mathrm{S}$, Piccart M, Campone M, Brain E, Macgrogan G, Petit T, Jassem J, Bibeau F, Blot E, Bogaerts J, Aguet M, Bergh J, Iggo R, Delorenzi M: A stroma-related gene signature

predicts resistance to neoadjuvant chemotherapy in breast cancer. Nat Med 2009, 15(1):68-74.

17. Loeffler M, Kruger JA, Niethammer AG, Reisfeld RA: Targeting tumor-associated fibroblasts improves cancer chemotherapy by increasing intratumoral drug uptake. J Clin Invest 2006, 116(7):1955-1962.

18. Shekhar MP, Santner S, Carolin KA, Tait L: Direct involvement of breast tumor fibroblasts in the modulation of tamoxifen sensitivity. Am J Pathol 2007, 170(5):1546-1560.
19. Martinez-Outschoorn UE, Goldberg A, Lin Z, Ko YH, Flomenberg N, Wang C, Pavlides S, Pestell RG, Howell A, Sotgia F, Lisanti MP: Anti-estrogen resistance in breast cancer is induced by the tumor microenvironment and can be overcome by inhibiting mitochondrial function in epithelial cancer cells. Cancer Biol Ther 2011, 12(10):924-938.

20. Sims GP, Rowe DC, Rietdijk ST, Herbst R, Coyle AJ: HMGB1 and RAGE in inflammation and cancer. Annu Rev Immunol 2010, 28:367-388.

21. Ellerman JE, Brown CK, de Vera M, Zeh HJ, Billiar T, Rubartelli A, Lotze MT: Masquerader: high mobility group box-1 and cancer. Clin Cancer Res 2007, 13(10):2836-2848.

22. Dong Xda E, Ito N, Lotze MT, Demarco RA, Popovic P, Shand SH, Watkins S, Winikoff S, Brown CK, Bartlett DL, Zeh HJ3rd: High mobility group box I (HMGB1) release from tumor cells after treatment: implications for development of targeted chemoimmunotherapy. J Immunother 2007, 30(6):596-606.

23. Ito N, DeMarco RA, Mailliard RB, Han J, Rabinowich H, Kalinski P, Stolz DB, Zeh HJ 3rd, Lotze MT: Cytolytic cells induce HMGB1 release from melanoma cell lines. J Leukoc Biol 2007, 81(1):75-83.

24. Lee H, Song M, Shin N, Shin CH, Min BS, Kim HS, Yoo JS, Kim H: Diagnostic significance of serum HMGB1 in colorectal carcinomas. PLoS One 2012, 7(4):e34318

25. Jube S, Rivera ZS, Bianchi ME, Powers A, Wang E, Pagano I, Pass HI, Gaudino G, Carbone $\mathrm{M}$, Yang $\mathrm{H}$ : Cancer cell secretion of the DAMP protein HMGB1 supports progression in malignant mesothelioma. Cancer Res 2012, 72(13):3290-3301.

26. Apetoh L, Ghiringhelli F, Tesniere A, Obeid M, Ortiz C, Criollo A, Mignot G, Maiuri MC, Ullrich E, Saulnier P, Yang H, Amigorena S, Ryffel B, Barrat FJ, Saftig P, Levi F, Lidereau R, Nogues C, Mira JP, Chompret A, Joulin V, Clavel-Chapelon F, Bourhis J, André F, Delaloge S, Tursz T, Kroemer G, Zitvogel L: Toll-like receptor 4-dependent contribution of the immune system to anticancer chemotherapy and radiotherapy. Nat Med 2007, 13(9):1050-1059.

27. Wang $\mathrm{H}$, Bloom $\mathrm{O}$, Zhang M, Vishnubhakat JM, Ombrellino M, Che J, Frazier A, Yang $\mathrm{H}$, Ivanova S, Borovikova L, Manogue KR, Faist E, Abraham E, Andersson J, Andersson U, Molina PE, Abumrad NN, Sama A, Tracey KJ: HMG-1 as a late mediator of endotoxin lethality in mice. Science 1999, 285(5425):248-251.

28. Bartling B, Fuchs C, Silber RE, Simm A: Fibroblasts mediate induction of high mobility group box protein 1 in lung epithelial cancer cells by diffusible factors. Int J Mol Med 2007, 20(2):217-224.

29. Luo Y, Chihara Y, Fujimoto K, Sasahira T, Kuwada M, Fujiwara R, Fujii K, Ohmori $H$, Kuniyasu $H$ : High mobility group box 1 released from necrotic cells enhances regrowth and metastasis of cancer cells that have survived chemotherapy. Eur J Cancer 2013, 49(3):741-751.

30. Xing F, Saidou J, Watabe K: Cancer associated fibroblasts (CAFs) in tumor microenvironment. Front Biosci 2010, 15:166-179.

31. Castells M, Thibault B, Delord JP, Couderc B: Implication of tumor microenvironment in chemoresistance: tumor-associated stromal cells protect tumor cells from cell death. Int J Mo/ Sci 2012, 13(8):9545-9571.

32. Tiago M, Oliveira EM, Brohem CA, Pennacchi PC, Paes RD, Haga RB, Campa A Barros SB, Smalley KS, Silvya ME: Fibroblasts protect melanoma cells from the cytotoxic effects of doxorubicin. Tissue Eng Part A 2014, 20(17-18):2412-2421.

33. Nakagawa H, Liyanarachchi S, Davuluri RV, Auer H, Martin EW Jr, de la Chapelle A, Frankel WL: Role of cancer-associated stromal fibroblasts in metastatic colon cancer to the liver and their expression profiles. Oncogene 2004, 23(44):7366-7377.

34. Al-Rakan MA, Colak D, Hendrayani SF, Al-Bakheet A, Al-Mohanna FH, Kaya N, Al-Malik O, Aboussekhra A: Breast stromal fibroblasts from histologically normal surgical margins are pro-carcinogenic. J Pathol 2013, 231(4):457-465.

35. Sarrio D, Rodriguez-Pinilla SM, Hardisson D, Cano A, Moreno-Bueno G, Palacios J: Epithelial-mesenchymal transition in breast cancer relates to the basal-like phenotype. Cancer Res 2008, 68(4):989-997.

36. Jeong $H$, Ryu YJ, An J, Lee Y, Kim A: Epithelial-mesenchymal transition in breast cancer correlates with high histological grade and triple-negative phenotype. Histopathology 2012, 60(6B):E87-E95.

37. Chuaysri C, Thuwajit P, Paupairoj A, Chau-In S, Suthiphongchai T, Thuwajit C: Alpha-smooth muscle actin-positive fibroblasts promote biliary cell proliferation and correlate with poor survival in cholangiocarcinoma. Oncol Rep 2009, 21(4):957-969.

38. Tabata C, Shibata E, Tabata R, Kanemura S, Mikami K, Nogi Y, Masachika E, Nishizaki T, Nakano T: Serum HMGB1 as a prognostic marker for malignant pleural mesothelioma. BMC Cancer 2013, 13:205.

39. Yan W, Chang $Y$, Liang $X$, Cardinal JS, Huang H, Thorne SH, Monga SP, Geller DA, Lotze MT, Tsung A: High-mobility group box 1 activates 
caspase-1 and promotes hepatocellular carcinoma invasiveness and metastases. Hepatology 2012, 55(6):1863-1875.

40. Willenbrock S, Braun O, Baumgart J, Lange S, Junghanss C, Heisterkamp A, Nolte I, Bullerdiek J, Murua Escobar H: TNF-alpha induced secretion of HMGB1 from non-immune canine mammary epithelial cells (MTH53A). Cytokine 2012, 57(2):210-220.

41. Hao Q, Du XQ, Fu X, Tian J: Expression and clinical significance of HMGB1 and RAGE in cervical squamous cell carcinoma. Zhonghua Zhong Liu Za Zhi 2008, 30(4):292-295.

42. Wild CA, Brandau S, Lotfi R, Mattheis S, Gu X, Lang S, Bergmann C: HMGB1 is overexpressed in tumor cells and promotes activity of regulatory $\mathrm{T}$ cells in patients with head and neck cancer. Oral Oncol 2012, 48(5):409-416.

43. Wu D, Ding Y, Wang S, Zhang Q, Liu L: Increased expression of high mobility group box 1 (HMGB1) is associated with progression and poor prognosis in human nasopharyngeal carcinoma. J Pathol 2008, 216(2):167-175.

44. Meyer A, Staratschek-Jox A, Springwald A, Wenk H, Wolf J, Wickenhauser C, Bullerdiek J: Non-Hodgkin lymphoma expressing high levels of the danger-signalling protein HMGB1. Leuk Lymphoma 2008, 49(6):1184-1189.

45. Belge G, Meyer A, Klemke M, Burchardt K, Stern C, Wosniok W, Loeschke S, Bullerdiek J: Upregulation of HMGA2 in thyroid carcinomas: a novel molecular marker to distinguish between benign and malignant follicular neoplasias. Genes Chromosomes Cancer 2008, 47(1):56-63.

46. Flohr AM, Rogalla P, Meiboom M, Borrmann L, Krohn M, Thode-Halle B, Bullerdiek J: Variation of HMGB1 expression in breast cancer. Anticancer Res 2001, 21(6A):3881-3885.

47. Brezniceanu ML, Volp K, Bosser S, Solbach C, Lichter P, Joos S, Zornig M: HMGB1 inhibits cell death in yeast and mammalian cells and is abundantly expressed in human breast carcinoma. FASEB J 2003, 17(10):1295-1297.

48. Kostova N, Zlateva S, Ugrinova I, Pasheva E: The expression of HMGB1 protein and its receptor RAGE in human malignant tumors. Mol Cell Biochem 2010, 337(1-2):251-258.

49. Todorova J, Pasheva E: High mobility group B1 protein interacts with its receptor RAGE in tumor cells but not in normal tissues. Oncol Lett 2012, 3(1):214-218.

50. Ranzato E, Patrone M, Pedrazzi M, Burlando B: Hmgb1 promotes wound healing of 3 T3 mouse fibroblasts via RAGE-dependent ERK1/2 activation. Cell Biochem Biophys 2010, 57(1):9-17.

51. Hou CH, Fong YC, Tang CH: HMGB-1 induces IL-6 production in human synovial fibroblasts through c-Src, Akt and NF-kappaB pathways. J Cell Physiol 2011, 226(8):2006-2015.

52. Liu L, Yang M, Kang R, Wang Z, Zhao Y, Yu Y, Xie M, Yin X, Livesey KM, Loze MT, Tang D, Cao L: DAMP-mediated autophagy contributes to drug resistance. Autophagy 2011, 7(1):112-114.

53. Liu L, Yang M, Kang R, Wang Z, Zhao Y, Yu Y, Xie M, Yin X, Livesey KM, Lotze MT, Tang D, Cao L: HMGB1-induced autophagy promotes chemotherapy resistance in leukemia cells. Leukemia 2011, 25(1):23-31.

54. Chittaranjan S, Bortnik S, Dragowska WH, Xu J, Abeysundara N, Leung A, Go NE, DeVorkin L, Weppler SA, Gelmon K, Yapp DT, Bally MB, Gorski SM: Autophagy inhibition augments the anticancer effects of epirubicin treatment in anthracycline-sensitive and -resistant triple-negative breast cancer. Clin Cancer Res 2014, 20(12):3159-3173.

55. Smolarczyk R, Cichon T, Matuszczak S, Mitrus I, Lesiak M, Kobusinska M, Kamysz W, Jarosz M, Sieron A, Szala S: The role of Glycyrrhizin, an inhibitor of HMGB1 protein, in anticancer therapy. Arch Immunol Ther Exp (Warsz) 2012, 60(5):391-399.

56. Guerriero JL, Ditsworth D, Catanzaro JM, Sabino G, Furie MB, Kew RR, Crawford HC, Zong WX: DNA alkylating therapy induces tumor regression through an HMGB1-mediated activation of innate immunity. J Immunol 2011, 186(6):3517-3526.

57. Stoetzer OJ, Fersching DM, Salat C, Steinkohl O, Gabka CJ, Hamann U, Braun M, Feller AM, Heinemann V, Siegele B, Nagel D, Holdenrieder S: Circulating immunogenic cell death biomarkers HMGB1 and RAGE in breast cancer patients during neoadjuvant chemotherapy. Tumour Biol 2013, 34(1):81-90.

doi:10.1186/1471-2407-14-955

Cite this article as: Amornsupak et al:: Cancer-associated fibroblasts induce high mobility group box 1 and contribute to resistance to doxorubicin in breast cancer cells. BMC Cancer 2014 14:955.

\section{Submit your next manuscript to BioMed Central and take full advantage of:}

- Convenient online submission

- Thorough peer review

- No space constraints or color figure charges

- Immediate publication on acceptance

- Inclusion in PubMed, CAS, Scopus and Google Scholar

- Research which is freely available for redistribution 